\title{
Erratum to "Gastric and Rectal Metastases from Malignant Melanoma Presenting with Hypochromic Anemia and Treated with Immunotherapy"
}

\author{
Pietro Genova, ${ }^{1}$ Maria Sorce, ${ }^{2}$ Daniela Cabibi, ${ }^{3}$ Gaspare Genova, ${ }^{1}$ Vittorio Gebbia $\left(\mathbb{D},{ }^{4}\right.$ \\ Daniele Galanti, ${ }^{5}$ Chiara Ancona, ${ }^{5}$ and Mara Rosaria Valerio ${ }^{5}$ \\ ${ }^{1}$ Surgical Oncology Unit, Dipartimento di Scienze Chirurgiche, Oncologiche e Stomatologiche, University of Palermo, \\ Palermo, Italy \\ ${ }^{2}$ Dermatology Unit, Dipartimento Biomedico di Medicina Interna e Specialistica (DiBiMIS), University of Palermo, \\ Palermo, Italy \\ ${ }^{3}$ Pathology Unit, Dipartimento di Scienze Chirurgiche, Oncologiche e Stomatologiche, University of Palermo, Palermo, Italy \\ ${ }^{4}$ Medical Oncology Unit, La Maddalena Clinic for Cancer, Dipartimento Biomedico di Medicina Interna e Specialistica \\ (DiBiMIS), University of Palermo, Palermo, Italy \\ ${ }^{5}$ Medical Oncology Unit, Dipartimento di Scienze Chirurgiche, Oncologiche e Stomatologiche, University of Palermo, \\ Palermo, Italy \\ Correspondence should be addressed to Vittorio Gebbia; vittorio.gebbia@gmail.com
}

Received 23 January 2018; Accepted 31 January 2018; Published 27 February 2018

Copyright (c) 2018 Pietro Genova et al. This is an open access article distributed under the Creative Commons Attribution License, which permits unrestricted use, distribution, and reproduction in any medium, provided the original work is properly cited.

In the article titled "Gastric and Rectal Metastases from Malignant Melanoma Presenting with Hypochromic Anemia and Treated with Immunotherapy" [1], the name of the sixth author was given incorrectly as Daniela Galanti. The author's name should have been written as Daniele Galanti. The revised authors' list is shown above.

\section{References}

[1] P. Genova, M. Sorce, D. Cabibi et al., "Gastric and rectal metastases from malignant melanoma presenting with hypochromic anemia and treated with immunotherapy," Case Reports in Oncological Medicine, vol. 2017, Article ID 2079068, 4 pages, 2017. 


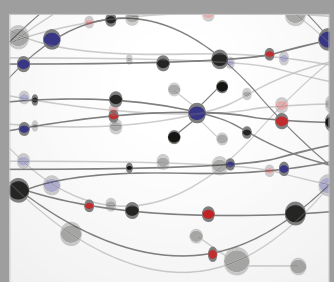

The Scientific World Journal
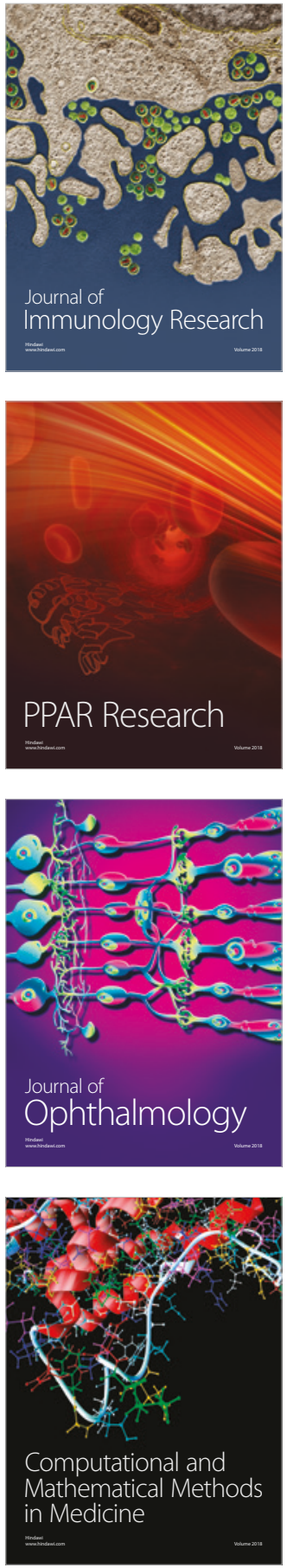

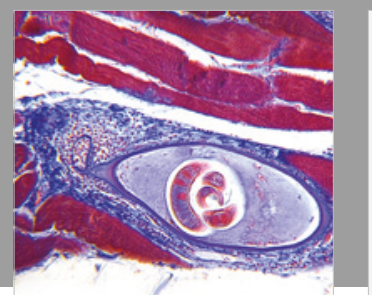

Gastroenterology Research and Practice

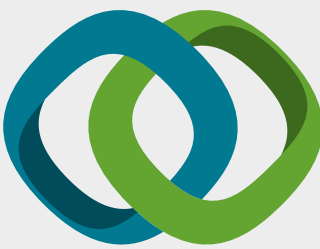

\section{Hindawi}

Submit your manuscripts at

www.hindawi.com
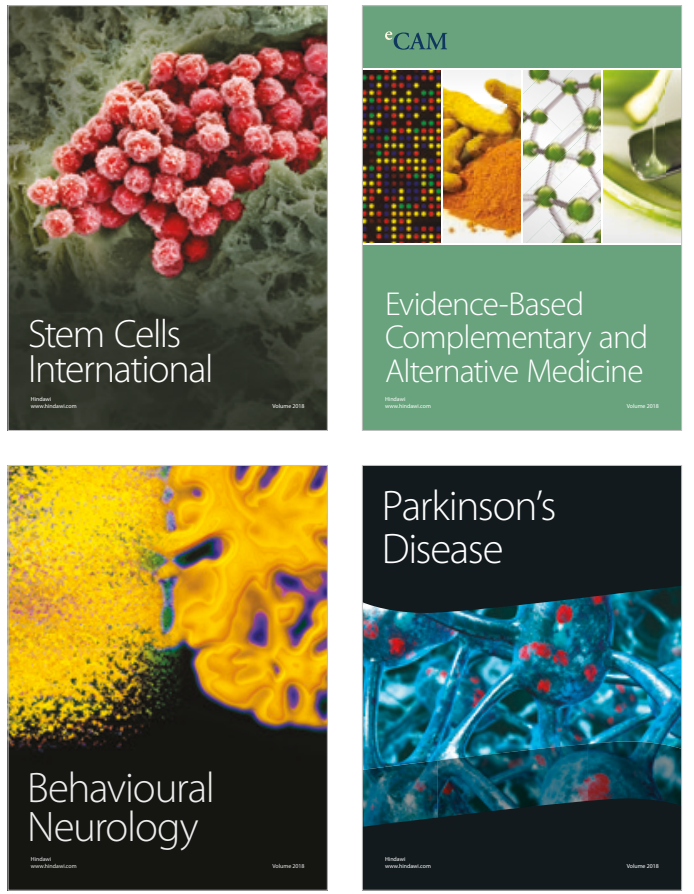

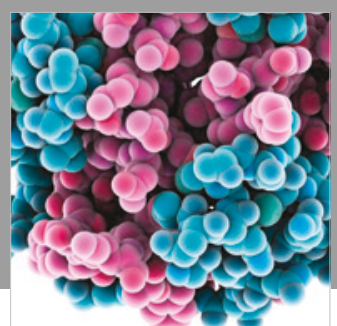

ournal of

Diabetes Research

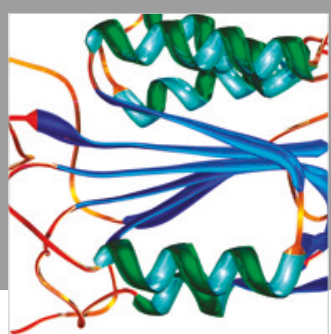

Disease Markers
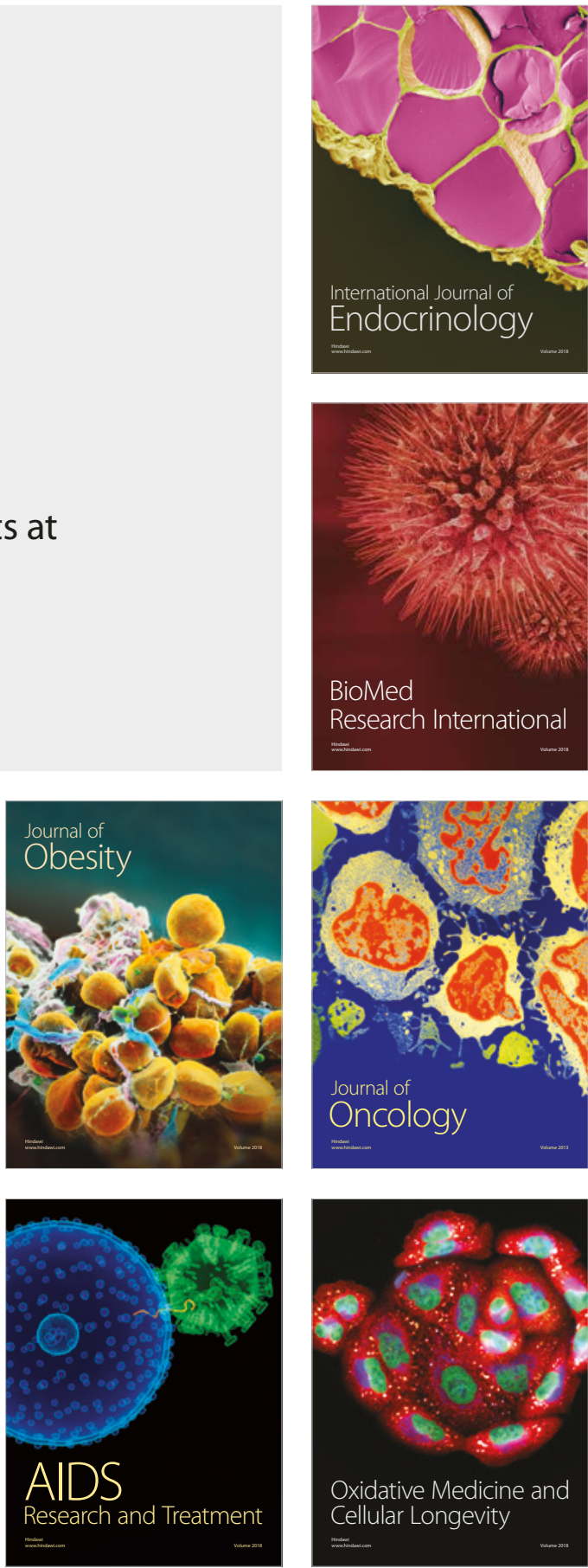